Intecoms: Journal of Information Technology and Computer Science

Volume 1 Nomor 2, Desember 2018

e-ISSN : 2614-1574

p-ISSN : 2621-3249

DOI : https://doi.org/10.31539/intecoms.v1i2.288

\title{
APLIKASI GAME EDUKASI PADA ANAK USIA 5 SAMPAI 10 TAHUN DENGAN METODE IMAGE MANIPULATION
}

\section{EDUCATION GAME APPLICATION IN CHILDREN AGE 5 TO 10 YEARS WITH IMAGE MANIPULATION METHOD}

\author{
Irohito Nozomi \\ Universitas Putra Indonesia YPTK Padang \\ irohito_nozomi@upiyptk.ac.id
}

\begin{abstract}
At present we have found a lack of learning media applications that can attract the attention of children in the learning process, especially children aged 5 to 10 years. Educational games need to be developed, because learning games have advantages over conventional learning. The main advantages of learning games are in the appearance of the real problem. Learning games are designed to be examples of existing problems so that values or knowledge can be used to solve the problem. This learning simulation game aims for entertainment and can be used as one of the media that overcomes boredom and boredom in the learning process and educates students. Based on the pattern that this learning game has, users are required to learn to complete the existing learning. Promotes learning games that are superior in some respects when compared to old learning methods. One obvious advantage is animation that can increase children's memory, so children can store learning material for a long time, when compared to conventional learning.
\end{abstract}

Keywords : Education Game, Children, Image Manipulation

\section{ABSTRAK}

Saat ini kita banyak mendapati minimnya aplikasi media pembelajaran yang bisa menarik perhatian anakanak dalam proses pembelajaran khususnya anak usia 5 sampai 10 tahun. Game edukasi perlu dikembangkan, karena game pembelajaran memiliki kelebihan dibandingkan dengan pembelajaran konvensional. Kelebihan utama dari game pembelajaran terdapat pada tampilan dari permasalahan sesungguhnya. Game pembelajaran didesain untuk menjadi contoh dari masalah yang ada sehingga didapatkan nilai atau ilmu yang dapat bergunakan untuk menyelesaikan masalah tersebut. Game simulasi pembelajaran ini bertujuan untuk hiburan dan dapat digunakan sebagai salah satu media yang mengatasi kejenuhan dan kebosanan dalam proses pembelajaran serta mendidik para peserta didik. Berdasarkan pola yang dipunyai oleh game pembelajaran ini, pengguna diharuskan belajar agar dapat menyelesaikan pembelajaran yang ada. Mengemukakan game pembelajaran yang unggul dalam beberapa hal jika dibandingkan dengan metode pembelajaran yang lama. Salah satu kelebihan yang jelas ialah animasi yang mampu menaikan daya ingat anak, sehingga anak bisa menyimpan materi pembelajaran dalam waktu lama, apabila dibandingkan dengan pembelajaran yang lama.

Kata Kunci: Permainan Edukasi, Anak-anak, Manipulasi Gambar

\section{PENDAHULUAN}

Perkembangan yang terjadi pada teknologi saat ini, memberikan pengaruh pada semua aktifitas pembelajaran dan pengajaran terhadap anak. Bagaimana jika kita melibatkan teknologi pada proses pembelajaran tersebut, tentu menjadi sesuatu yang baru dan menyenangkan. Sebagai contoh, bentuk pengajaran yang biasanya metode pembelajaran menggunakan buku-buku baik menggunakan buku bergambar atau sejenisnya yang mempunyai kelemahan seperti mudah rusak dan juga kurang menarik bagi anak usia 5 sampai 10 tahun, dapat dibantu dengan adanya bentuk nyata pemanfaaatan teknologi 
pada pendidikan. Saat ini kita banyak mendapati minimnya aplikasi media pembelajaran yang bisa menarik perhatian anak-anak dalam proses pembelajran khususnya anak usia dini.

Game pembelajaran sangat bagus untuk dikembangkan, karena mempunyai kelebihan. Game pembelajaran bertujuan untuk dapat menyenangkan pengguna saat digunakan sebagai salah satu media yang mampu mengatasi kejenuhan dan kebosanan dalam proses pembelajaran. Berdasarkan bentuk dari game ini, pengguna diharuskan belajar agar mampu menyelesaikan pembelajaran yang ada. Mengemukakan game pembelajaran agar dapat unggul dalam beberapa hal jika dibandingkan dengan pembelajaran yang lama. Salah satu kelebihan yang jelas ialah animasi yang mampu menaikan kemampuan mengingat anak, sehingga anak dapat mengingat materi pelajaran dalam waktu lama, jika dibandingkan dengan pengajaran yang lama. Seperti game edukasi pembelajaran membaca pada anak pra sekolah berbasis android, pengenalan bentuk dan warna benda pada anak, Game edukasi Cerita untuk anak usia dini, Pembelajaran do'a-do'a harian berbasis game, permainan dalam pencegahan penyakit malaria (Fitriyah, 2015; Dyta, 2015; Fatimah \& Apriani, 2014; Hermansyah dkk, 2015; Mahafi \& Hermawan, 2013).

Bagaimana membuat aplikasi media pembelajaran yang bisa menarik perhatian anak-anak dalam proses pembelajaran khususnya anak usia dini.

Game pembelajaran adalah permainan yang didesain dan dibuat supaya merangsang cara berpikir termasuk meningkatkan kosentrasi dan memecahkan masalah. Game pembelajaran merupakan salah satu jenis media yang dapat digunakan untuk memberikan pengajaran, menambah ilmu penggunanya melalui suatu media unik dan menarik. Game pembelajaran merupakan bentuk permainan yang berguna untuk menunjang proses pembelajaran yang lebih menyenangkan dan menarik (Hermansyah dkk, 2015).

Game sering kali dituduh memberikan pengaruh negatif terhadap anak. Sebenarnya, game memiliki kegunaan dan dampak baik bagi anak, sehingga anak dapat mengenal teknologi, pembelajaran untuk mengikuti arahan dan aturan, melatih menyelesaikan masalah, melatih saraf motorik dan keterampilan spesial, menjalin komunikasi saat bermain serta memberikan hiburan bagi anak (Putra dkk, 2016).

Permainan didesain dan dibuat sebagai perangsang daya pikir termasuk peningkatkan kemampuan konsentrasi dan memecahkan masalah. Pada permainan, tidak cuma pokok pelajaran saja yang dikembangkan,nilai sopan santun, ketangkasan, dan kecerdasan didapat sekaligus. Pembelajaran melalui permainan akan membantu siswa mengurangi kejenuhan, dan mengembangkan kreatifitasnya (Novaliendry, 2013).

\section{METODE PENELITIAN}

Game edukasi berupa media pembelajaran interaktif yang disampaikan nanti berupa animasi, text, dan audio.

Penggunaan aplikasi ini dibatasi berupa mencari barang tersembunyi yang ada pada stage game dengan waktu yang di batasi,yang bertujuan untuk menghilangkan kejenuhan yang terjadi pada proses belajar mengajar.

Perancangan dan pembuatan game edukasi pada proses belajar mengajar dengan menggunakan multimedia interaktif memakai adobe flash cs6 pada aplikasi skill game mencari barang yang tersembunyi. Dan beberapa software 
pendukung seperti : Adobe Photoshop CS6, Corel Draw X4, Frutty Loop Studio 11.

Perancangan game ini dengan menggunakan konsep menyamarkan gambar atau menyembunyikan gambar yang akan dicari sesuai clue yang ada dengan menggunakan tujuan dari Metode Image Manipulation.

\section{Learning Technology Standar Architecture (LTSA)}

LTSA adalah standar internasional dimana sistem pembelajaran yang telah ditingkatkan berdasarkan IEEE 1484 Learning Standards Committee (LTSC) oleh Farance Incorporational, divisi Edutool, ialah arsitektur tertinggi yang memiliki fokus pada masalah teknologi pembelajaran elektronik, intruksi komputer dan lain-lain. (Yusuf dkk, 2010).

\section{Arsitektur Sistem LTSA}

Ada lima spesifikasi lapisan (layer) LTSA, akan tetapi hanya layer ketiga yang memiliki sifat normative. Dari tiap-tiap layer menampilkan sistem pada level yang berbeda-beda.

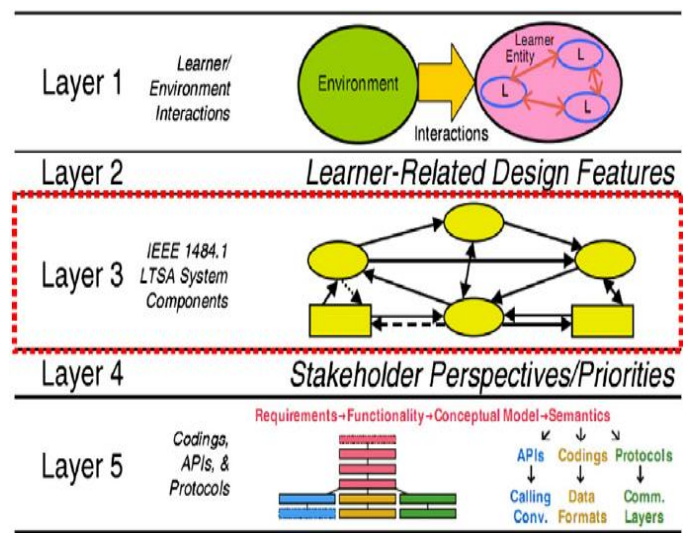

Gambar. 1 Arsitektur LTSA

Layer pertama ialah Learner and Environment Interaction. Layer ini fokus kepada akuisisi, transfer, pertukaran, formulasi dan penemuan pengetahuan atauinformasi melalui interaksi dengan lingkungan.
Layer kedua Learner Related DesignFeatures. Layer yang memiliki fokus terhadap pengaruh yang dimiliki learner rancangan pembelajaran.

Layer ketiga System Components. Layer ini menceritakan bagian yang terdapat pada layer kedua.

Layer keempat Implementation Perspective and Priorities. Layer ini menceritakan sistem pembelajaran dari bermacam sudut pandang dan mengacu pada layer ketiga. Setiap stakeholder mempunyai perspektif tidak sama dengan pembelajaran. Analisis dengan sudut pandang yang berbeda dapat menghasilkan verifikasi dan validasi komponen LTSA pada sistem.

\section{Layer kelima Operational} Componentsand Interoperabilit. Menceritakan komponen dan antar muka yang bersifat generic dari arsitektur pembelajaran berbasis teknologi informasi yang diidentifikasi pada layer empat.

\section{Komponen Sistem LTSA}

LTSA memiliki 5 layer, akan tetapi cuma layer ketiga yang merupakan layer normatif, sedangkan yang lain merupakan layer informatif. Layer normative merupakan istilah yang terdapat pada LTSA sebagai bentuk spesifikasi sistem secara teknis terhadap penerapan yang akan dilakukan. Sedangkan layer Informatif merupakan LTSA berguna untuk rancangan arsitekturnya, tapi tidak diperlukan untuk mengerti isi standar LTSA.

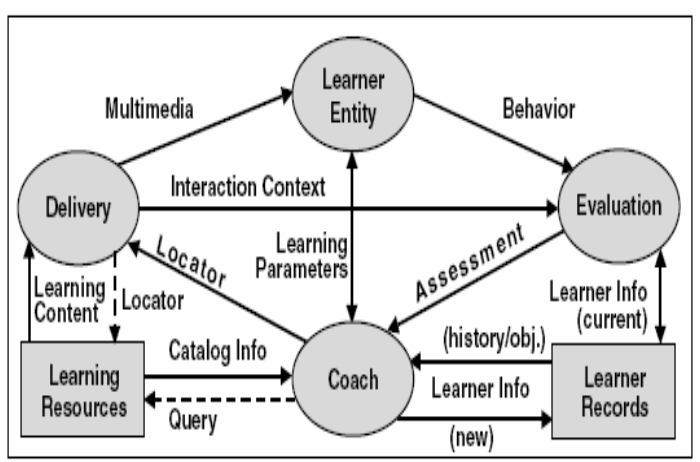

Gambar 2.Arsitektur LTSA 
Layer ini merupakan sebuah sistem dengan berbagai komponen yang mempresentasikan pengorganisasian sebuah proses pembelajaran dari sudut pandang proses dan data flow. Proses didalam kompenen sistem LTSA dideskripsikan dengan batasan-batasan berupa input, proses (secara fungsionalitas) dan output. Proses pada kompenen sistem LTSA terdiri dari entitas pelajar (learner entity), evaluasi (evaluation), pelatih (coach)dan (delivery). Media penyimpanan data dideskripsikan dengan tipe dari informasi yang disimpan. Tempat penyimpanan data terdiri dari sumber daya pembelajaran (learner resources) dan data hasil pembelajaran (learner record).

Aliran data dideskripsikan berdasarkan konektifitas(satu arah, dua arah, konektifitas statis, dinamis dan sebagainya) dan tipe informasi yang dialirkan. Aliran data terdiri dari query, info catalog (catalog info), materi pembelajaran (learning content), locator, multimedia, konteks interaksi (interaction centext), perilaku (behavior), penilaian (assessment), parameter pembelajaran (learning parameters) dan informasi pelajar (learner information).

\section{Learning Resource}

Sumber materi yang dapat dijadikan referensi atau acuan.

\section{Coach}

Mengajarkan materi soal dan menunjukan jawaban pada evaluasi yang diberikan.

\section{Delivery Media}

Interface bagi learner entity untuk mengakses materi pembelajaran/latihan soal.

\section{Learner Entity}

Learner Entity mempunyai input dan output seperti:

Input yang ada pada proses learner entity yaitu materi dan soal latihan. Output berupa jawaban yang dikerjakan kemudian diproses sebagai evaluasi.

\section{Evaluation}

Pada Evaluation terdapat input dan output sebagai berikut :

Jawaban evaluasi dari eLearning yang diterapkan, oleh pengguna yang berinteraksi. Keluaran seperti nilai yang menjadi masukan bagi pelatih dan dapat diketahui juga oleh learner entity.

\section{Image Manipulation}

Image Manipulation adalah Cara untuk merubah, menambahkan dan memperindah tampilan gambar atau foto dari bentuk aslinya menjadi suatu bentuk yang memiliki nilai yang lebih. Bisa juga dikatakan seperti berilusi dengan foto melalui cara-cara digital atau analog.

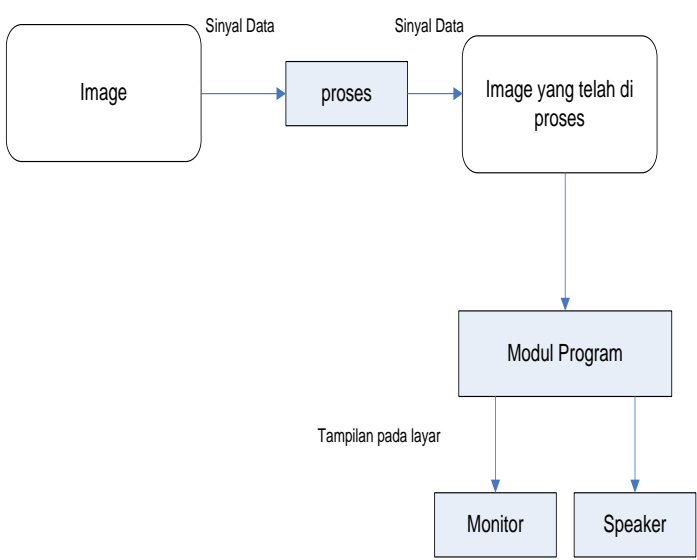

Gambar 3. Alur Image Manipulation 
HASIL DAN PEMBAHASAN Tampilan Halaman Menu Utama

Halaman Menu Utama merupakan halaman yang berisikan pilihan menu yaitu Start Game, Profile, Instruction, Exit.

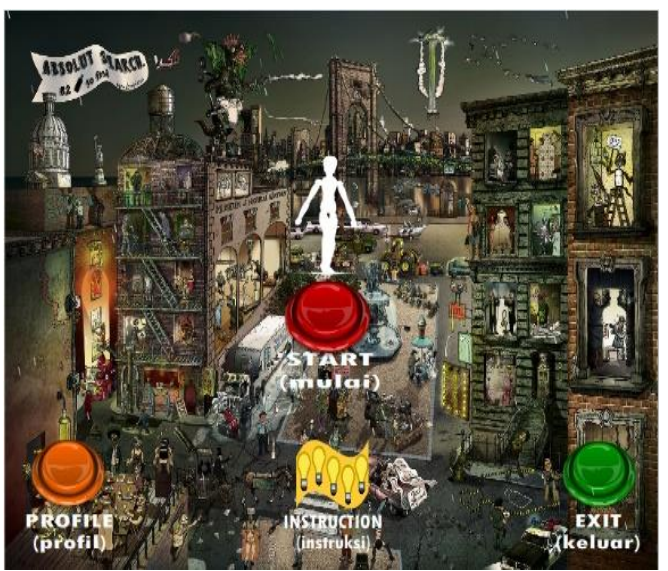

Gambar. 4 Tampilan Halaman Menu Utama

Terdapat button navigasi Start Game yang mengarahkan untuk memulai permainan, Profile akan mengarahkan ke halaman menu profile pembuat game, menu Instruction mengarahkan ke halaman petunjuk game, dan Exit untuk keluar dari halaman instruction.

\section{Tampilan Halaman Menu Profile}

Halaman menu profile merupakan halaman profile dari orang pembuat game. Pada Halaman profile juga terdapat button back yang berfungsi untuk kembali ke halaman utama game.

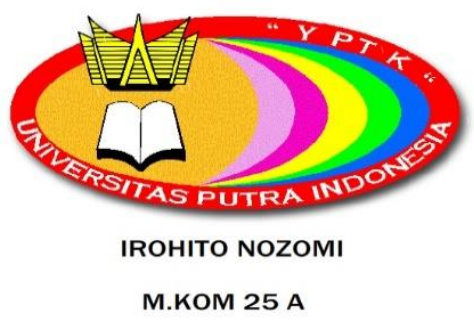

BACK

Gambar. 5 Tampilan Pada Menu Profile
Pada halaman profile ini terdapat foto logo Universitas Putra Indonesia "YPTK" Padang, dan nama dari mahasiswa pembuat game ini.

\section{Tampilan Halaman Instruction}

Tampilan halaman instruction merupakan tampilan menu yang berisikan petunjuk dan tata cara memainkan game interaktif.

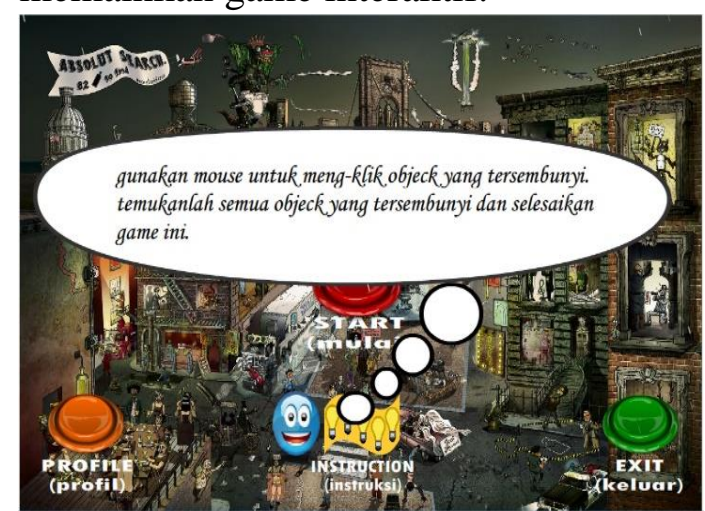

Gambar. 6 Tampilan Halaman Instruction

Pada halaman instruction terdapat petunjuk cara memainkan game interaktif.

\section{Tampilan Halaman Clue Sebelum Memulai Stage 1}

Tampilan Halaman Sebelum memulai stage 1 terdapat clue atau benda yang akan dicari pada permainan stage 1 dan juga terdapat Tombol next.

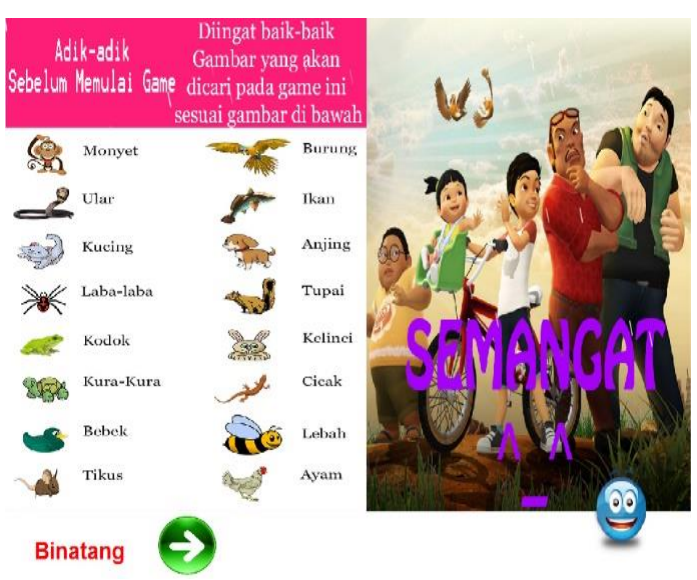

Gambar. 7 Tampilan Halaman Clue Sebelum Memulai Stage 1 


\section{Tampilan Halaman Game Stage 1}

Tampilan halaman stage 1 pada saat permainan game dimulai. Di sini userakan mencari gambar tersembunyi dengan batasan waktu yang di tentukan. Gambar yang di cari harus sesuai dengan clue yang telah ada.

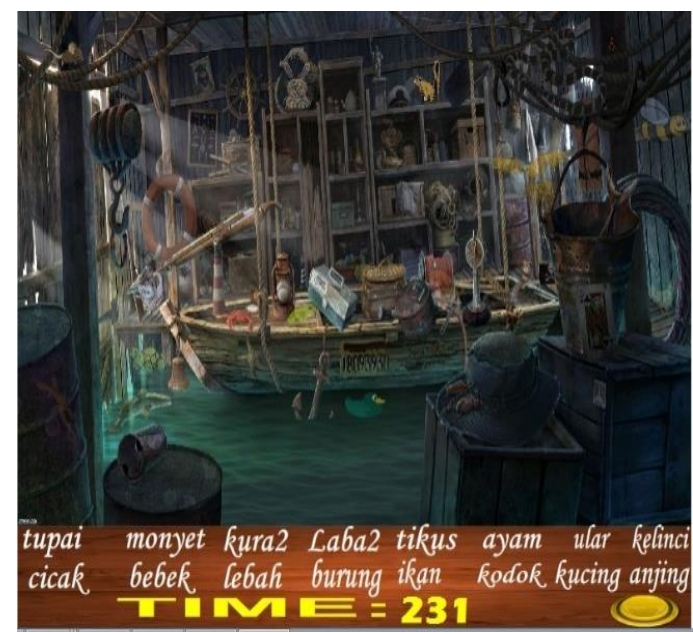

Gambar. 8 Tampilan Halaman Game Stage 1

Pada halaman game stage 1 terdapat 16 gambar tersembunyi yang akan dicari sesuai clue game yang ada dengan waktu pencarian yang terbatas.

\section{Tampilan Halaman Jika Game Telah Terselesaikan}

Jika user telah menemukan semua gambar tersembunyi dan juga telah menyelesaikan semua stage game ini maka akan lanjut ke halaman terakhir untuk penutupan game tersebut.

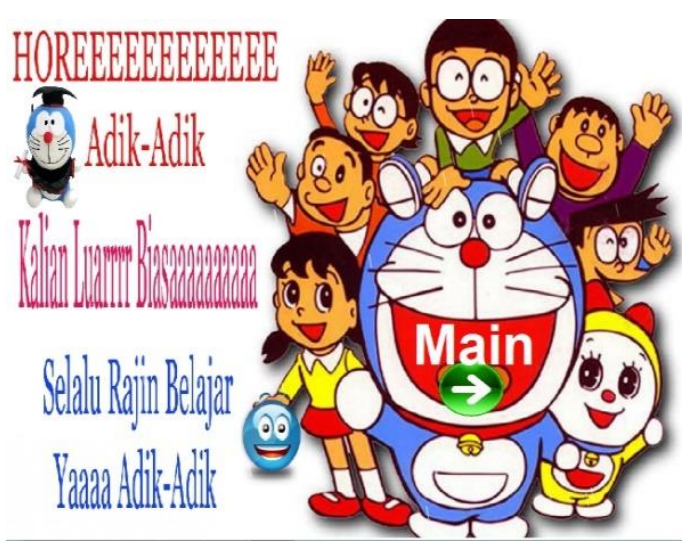

Gambar. 9 Tampilan Halaman Jika Game Telah Terselesaikan
Menurut Hurd dan Jenuings dalam Widiastuti dan Setiawan (2012) menjabarkan perancang yang baik haruslah memenuhi kriteria dari education game itu sendiri. Berikut kriteria dari sebuah education game, yaitu:

1. Nilai Menyeluruh (Overall Value)

Permainan terpusat pada rancangan dan waktu tunggu dari game. Aplikasi ini dibuat semenarik mungkin. Agar dapat menentukan waktunya, aplikasi ini memakai fitur timer.

2. Mudah Digunakan (Usability)

Dapat dipakai dan digunakan adalah hal penting bagi pembuatan game. Aplikasi ini membuat sistem dengan interface yang user friendly sehingga penggunabias dengan mudah menggunakan aplikasi.

3. Keakuratan (Accuracy)

Dapat diartikan sebagai mana kesuksesan model atau gambaran suatu game bisa dibuatkan ke dalam percobaan maupun rancangannya. Perancangan aplikasi diharapkan menyerupai modelgame pada tahapan perencanaan.

4. Kesesuaian (Appropriateness)

Isi dan rancangan game bias disesuaikan dengan keperluan pengguna. Aplikasi ini menyajikan menu dan fitur yang diperlukan penggunaagar menolong pengguna dalam menggunakan aplikasi.

5. Relevan (Relevance)

Menerapkan game ke pengguna. supaya mendapatkan hasil yang penting terhadap pengguna, sistem harus mengarahkan pengguna kepada pencapaian pembelajaran. Sebab aplikasi ini diperuntukan untuk anakanak, maka desain antar muka harus menyerupai dengan ketertarikan pengguna. 
6. Objektifitas (Objectives)

Merupakan usaha untuk mempelajari hasil kesuksesan atau kegagalan dari permainan.

7. Umpan Balik (Feedback)

Menolong pengguna bahwa permainan yang dilakukan sesuai atau tidak dengan objek yang ada pada game, Aplikasi ini menampilkan suara dan animasi yang menandakan keberhasilan atau kegagalan game (Novaliendry.D, 2013).

\section{SIMPULAN}

Berdasarkan perancangan dan pembuatan game edukasi multimedia interaktif dapat disimpulkan sebagai berikut:

1. Perancangan game edukasi multimedia interaktif ini dirancang dengan menggunakan aplikasi Adobe Flas CS6 dalam bentuk penggunaan teks, gambar, audio dan animasi.

2. Penggunaan game edukasi multimedia interaktif ini memberikan kemudahan kepada penggunanya, karena telah dirancang semudah mungkin dengan konsep user friendly.

3. Game edukasi multimedia interaktif ini dirancang dan dikembangkan sebagai media pembelajaran bagi orang tua dan guru yang praktis secara menarik yang diterapkan untuk anak usia dini masa sekolah ataupun masa pra sekolah. 


\section{DAFTAR PUSTAKA}

Dyta, S. E. (2015). Rancang Bangun Aplikasi Game Edukasi Anak untuk Mengenal Bentuk dan Warna Benda. Jurnal Fakultas Ilmu Komputer, 2(2)

Fatimah, S., \& Apriani, A. (2014). Rancang Bangun Aplikasi Edukasi Ceria Berbasis Android Sebagai Media Pembelajaran Untuk Anak Usia Dini. Jurnal Teknik Informatika, 1(1)

Fitriyah, B. (2015). Perancangan Game Edukasi Belajar Membaca pada Anak Pra Sekolah Berbasis Smartphone Android. Jurnal TEKNOIF, 3(1)

Hermansyah, Gustomi, L.F., dan, Nurhayati. (2015). Desain Aplikasi Pembelajaran Doa-doa Harian Berbasis Game Edukasi. Jurnal Sisfotek Global, 5(2)

Mahafi, A. G., \& Hermawan, G. (2013). Game Edukasi Penyakit Malaria dan Cara Pencegahannya. Jurnal Ilmiah Komputer dan Informatika (KOMPUTA), 2(2)

Novaliendry, D. (2013). Aplikasi Game Geografi Berbasis Multimedia Interaktif. Jurnal Teknologi Informasi dan Pendidikan, 6(2).

Putra, D. W., Nugroho, A. P., \&, Puspitarini, E. W. (2016). Game Edukasi Berbasis Android sebagai Media Pembelajaran Untuk Anak Usia Dini. Jurnal Informatika Merdeka Pasuruan, 1(1)

Widiastuti, N. I., dan Setiawan, I. (2012). Membangun Game EdukasiSejarahWalisongo, FTIK Unikom, Bandung.

Yusuf, M., Wahyuni, S., \& Saim, M. (2010). E-Learning Menggunakan Standar Learning Techonolgy System Architecture. Jurnal Simantec, 1(2) 